\title{
Reusing system of the ballast water
}

Kirollos Remon Mounir, Fady Bola Samir, Youssef Khaled Serageldin, Moataz Mohamed Sabry

Ismailia STEM high school 
Key words: Ballast water_Ships_ Magnets__Air source__ron feelings

\section{ABStract}

I ncreasing water consumption is a problem faced by the world; one of its solutions is reusing water. Reuse is about changing processes that result in polluted water byproducts so that the resulting water is usable again. Our major problem is to reuse unusable or polluted water. We are not treating the water, but we are changing processes to make water byproducts usable again in the same process or even a different process. Our solution is to reuse ballast water in transporting oil. Oil ships are heading from one country to another, and they are loaded with oil. These ships return to be loaded with ballast water instead of oil to prevent the risk of overturning this ship. In other words, the ballast water is used to make the ship stable which is the purpose of the ballast water to return to their original countries in peace. Our goal is to purify this ballast water mixed with oil residues by relying on the density difference. The first step is to place a source of solid air in the tanks to provide some bubbles inside the tank. Secondly, put some of the iron peels inside the tanks to stick these peels with the bubbles, then by a magnetic field attracts the pollutant bubbles attached to the iron scales, and the ballast water remains in the tank to be used again. Before writing a test plan, we demonstrated two design requirements. The first one is ballast water quality which has two parts the turbidity and oil, grease, and all extractable matter by chloroform in the water, while the second design requirement is the environmental impact. By making a test, the results were astounding because it achieved the design requirements that we put into making this project applicable for reusing this polluted water after purifying it.

\section{INTRODUCTION}

The world faces many challenges and SDGs that negatively affect the environment and its creatures, like ensuring affordable, reliable, sustainable, and modern energy for all, pollution, clean water, etc. The two significant challenges or SDGs that will be solved in our project are reducing pollution and manage and increase the source of water and the life below water.

There are many types of pollution, but the most influential types of pollution in general and on humans in particular: Air pollution, Soil Pollution, and our capstone problem Water Pollution as shown in figure 2 , the contamination of water bodies, usually because of human activities. One of these human activities is casting the water mixed with petrol and oil in oceans, which will be solved.

The world will need to improve other sources of clean water for agriculture and citizens' usage. In other words, the world will be hit by a severe drought that will lead to catastrophic economic consequences. As a result, purifying the water mixed with oil will allow reusing this water again in this process or another method considered a new water source.

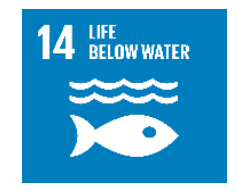

Figure 1

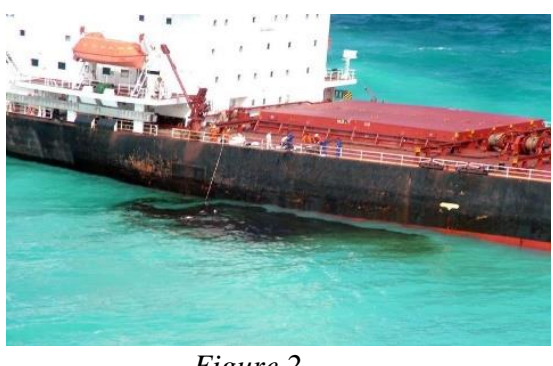

Figure 2

We searched for many prior solutions, but we choose the most successful one, which is Hampton Roads Sanitation District (HRSD). It is wastewater reuse and treatment utility that protects public health and water. In some parts of eastern Virginia, in conjunction with sea-level rise, is a problem that leads to flooded neighborhoods and vulnerable communities. Land subsidence is, in part, attributed to overdrawing groundwater aquifers. HRSD is addressing this by using highly treated and reusing wastewater to replenish the aquifers with up to 120 million gallons of water a day. This project will ultimately keep about 90 per cent of HRSD's wastewater discharge out of the Elizabeth, James, and York rivers.

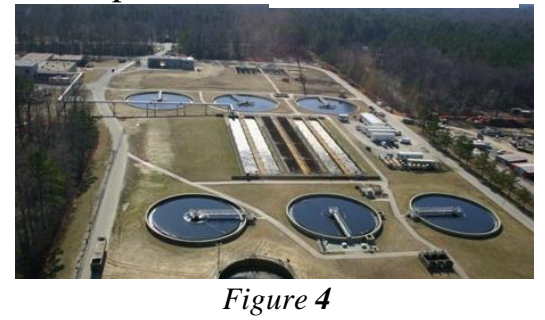


This project improves water quality and reuses it, helps communities adapt to sea level. It also has many weaknesses that we tried to avoid like, the estimated price is very high. So, developing countries cannot implement the project.

For choosing our solution, we used the collected data and the prior solutions to form our new project by mixing its strengths solution and avoiding its weakness. We had chosen the ballast water as the axis of our project. The ballast water is the fresh or salted water used in ships' tanks to make the ship stable and prevent the overturning of the vessel. In the oil ships, ballast water is mixed with oil that is in the tanks and returns to the oceans or rivers as wasted and polluted water. Our solution comes after studying this problem by purifying and treating the ballast water mixed with oil. The ballast water consumes an enormous amount of fresh water, as is shown in (graph 1). However, that massive amount can be reused again and save that lost water. Furthermore, it pollutes the oceans and rivers as it contains oil residue. This problem of the ballast water can be solved by reusing it. This solution addresses the design requirements of scientifically proven methods. By purifying the ballast water and exerting the oil from it, we could obtain good

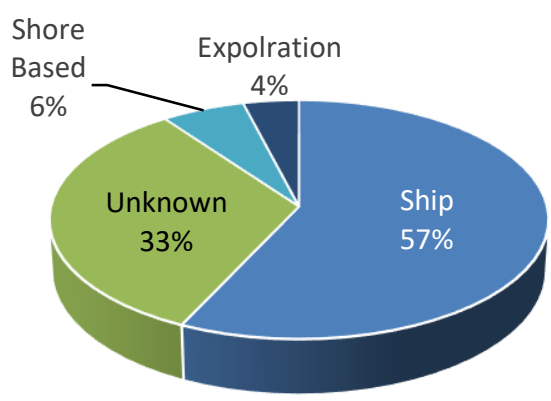

- Ship - Unknown " Shore Based - Expolration Graph 1 ballast water quality, which can be used again in the same field. A positive environmental impact can be obtained we prevent pouring mixed ballast water with oil in rivers and oceans. 


\section{MATERIALS AND METHODS OF MANUFACTURING THE PROJECT}

\section{i. MATERIALS}

\begin{tabular}{|c|c|c|c|}
\hline Name & Quantity & Description & Image \\
\hline Clear acrylic & $\begin{array}{l}6 \text { sheets to make a } \\
\text { box with a handle }\end{array}$ & $\begin{array}{l}\text { A transparent thermoplastic } \\
\text { homopolymer used as an impact resistant } \\
\text { alternative to glass }\end{array}$ & \\
\hline Air blower & 1 & $\begin{array}{l}\text { equipment or a device which increases } \\
\text { the velocity of air or gas when it is } \\
\text { passed through equipped impellers. }\end{array}$ & \\
\hline Iron filings & 250 grams & $\begin{array}{l}\text { very small pieces of iron that look like a } \\
\text { light powder. They are very often used to } \\
\text { show the direction of a magnetic field. }\end{array}$ & \\
\hline Magnets & $\begin{array}{l}4 \text { pieces of } \\
\text { magnets in the } \\
\text { form of cuboid }\end{array}$ & $\begin{array}{l}\text { A magnet is a material or object that } \\
\text { produces a (magnetic field). a force that } \\
\text { pulls on other ferromagnetic materials. }\end{array}$ & \\
\hline Pipes & 3 pipes & $\begin{array}{l}\text { A pipe is a tubular section or hollow } \\
\text { cylinder, used to convey substances } \\
\text { which can flow - liquids and gases } \\
\text { (fluids). }\end{array}$ & \\
\hline Oil & 1 liter & $\begin{array}{l}\text { Oil is a slippery liquid that comes from } \\
\text { minerals as well as animal and vegetable } \\
\text { fat. and do not mix with water }\end{array}$ & \\
\hline Silicone glue & $250 \mathrm{ml}$ & $\begin{array}{l}\text { a type of adhesive that contains silicon } \\
\text { and oxygen atoms, making it a good } \\
\text { water-resistant solution }\end{array}$ & \\
\hline
\end{tabular}




\section{ii. $\quad$ METHODS}

The following are the main points and logic considered in the methodology of the reusing system for the ballast water of transporting oil: -

- The project is based on a box made of six acrylic sheets in addition to a hand handle on the top sheet of the box.

- The dimensions of the prototype have been chosen with the following justification: Total length $=30 \mathrm{~cm}$, Width $=25 \mathrm{CM}$, Thickness $=4 \mathrm{~mm}$. All these lengths are also selected to withstand the air pressure generated by the different speeds of the air blower.

- The use of pipes of different shapes so that they are used:

(1) Two open pipes are used with an opening with a diameter of $5 \mathrm{~cm}$ and a height of $6 \mathrm{~cm}$ in one of the acrylic sheets to receive the air coming from the air impeller.

(2) the use of two other pipes with an opening slightly larger from.

(3) its amount $5.5 \mathrm{~cm}$ and at a higher height of $17.5 \mathrm{~cm}$ for the iron filings loaded with oils to be removed through these connected pipes

- Make a water tap so that the water is removed after cleaning it from the oil.

NOTE: this box is a simulation of the ballast water reuse system for transporting oil in the ship's tanks.

\section{iii. TEST PLAN}

Our test plan aims to succeed in collecting oil from water by a significant amount to reduce the turbidity and make water density closer to the pure water owning to reuse the water used in balancing and cleaning containers in the ships transfers petroleum oil.

Our design requirements were:

i. $\quad$ Reduce turbidity and make water density closer to pure water.

ii. Make an eco-friendly environment We wade a test on three samples with different three quantities of oil and iron fillings.

\section{Our test plan steps for each trial:}

i. We measure the amount of oil and the mass of iron fillings.

ii. Start adding oil to the water container.

iii. Use an air pump to stir the oil in water.

iv. Stop the air pump and start adding the iron fillings.

v. Start using the air pump again for seconds.

vi. Start moving magnetic bars on the outer surface of the container.

vii. After the magnetic bars collect iron fillings in the corners, rise them up and put them in the output tube.

viii. Wait for the output iron fillings that carry the amount of oil.

ix. Measure the output, then compare it with the first amount of iron filings, then calculate the difference between them to know the amount of output oil.

x. Try for another two trials to get an average. 


\section{RESULTS OF TESTING THE PROTOTYPE}

According to the testing results, when we put $100 \mathrm{gm}$ of oil and $120 \mathrm{gm}$ of iron feelings, the amount of iron feelings and the oil pollutants weights $164 \mathrm{gm}$. So, the amount of attracted oil is $44 \mathrm{gm}$ from the original amount that weighs $100 \mathrm{gm}$. By changing the amounts of the input of the oil and the iron feelings, I found that the project can attract $43 \%$ of the oily pollutants in water as it shown in Table 2 and Graph 2.

\begin{tabular}{|l|l|l|l|l|}
\hline Trials & $\begin{array}{l}\text { Amount of } \\
\text { inputted } \\
\text { iron filings. } \\
(X)\end{array}$ & $\begin{array}{l}\text { Amount Input } \\
\text { of the oil. }\end{array}$ & $\begin{array}{l}\text { Amount of iron } \\
\text { filings with the oil } \\
\text { that has been caried } \\
(Y)\end{array}$ & $\begin{array}{l}\text { Amount of the oil } \\
\text { has been caried. } \\
Y-X\end{array}$ \\
\hline$(1)$ & $140 \mathrm{gm}$ & $110 \mathrm{gm}$ & 183 & 46 \\
\hline$(2)$ & $120 \mathrm{gm}$ & $100 \mathrm{gm}$ & 164 & 44 \\
\hline$(3)$ & $100 \mathrm{gm}$ & $90 \mathrm{gm}$ & 139 & 39 \\
\hline
\end{tabular}

Table 2

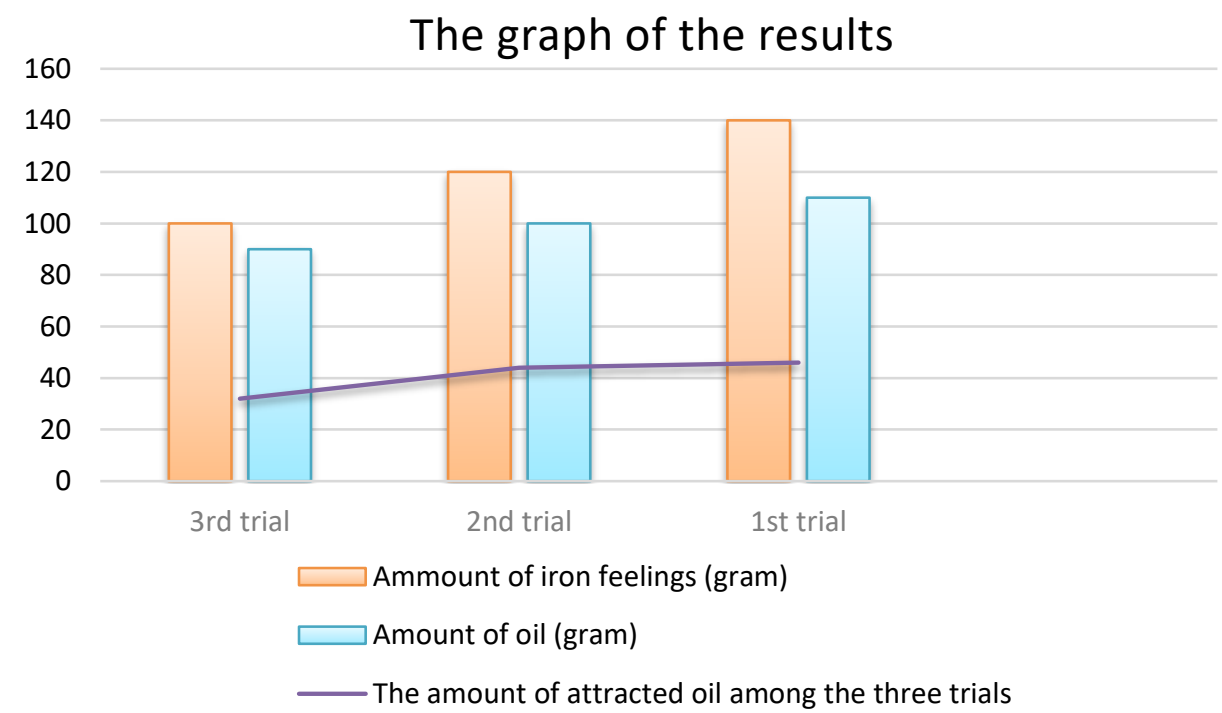

Graph 2 


\section{ANALYSIS}

Our project is a treating system of the ballast water resulting from the process of transportation of oil. To define the ballast water, we can say that ballast water is any solid or liquid brought on board a vessel to increase the draft, change the trim, regulate the stability, or maintain stress loads within acceptable limits. The ballast water is a global problem that affects all oil-exporting and importing countries, explaining that the problem lies in the design of the ship itself, and if it is empty, it floats and is driven by waves, adding, the ship must be heavy to submerge in the water and stabilize, so they are forced to replace the oil with water that is taken in the port of discharge as it shown in figure 5. In the case of transportation of oil, the ballast water is loaded with the

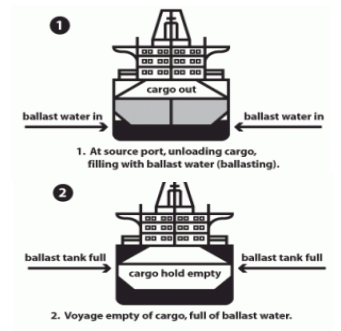
pollutants of oil. The problem is that the ballast water is placed in the ships' containers, so the oil mixes with the petroleum sediments on the walls of the containers.

After the ships are returned, the workers in this field throw the oily soiled water into the sea, which pollutes the seawater because oil has a toxic effect on marine organisms when they absorb it. The hydrocarbons that make up the oil accumulate in the fatty tissues, liver, and pancreas of fish, which kill humans after suffering cancer. It also negatively affects invertebrates, plankton, shellfish, mammals, marine birds, and coral reefs. That polluted water is thrown into the oceans or rivers. So, that water is considered wasted water. If we treated that water and reduced

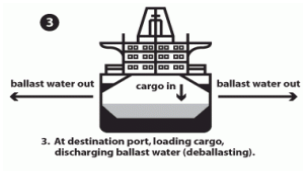

Figure 5 the percentage of oil in it, we would be able to reuse that water in the same field again.

Moreover, reduce the consumption of water in the usage of ballast water. Our project provides a treating system of the oily ballast water to reuse it again in the same field. The project depends on physical properties as the differences in the density between the oily pollutants and the water. The oily pollutants will float on the water's surface, so we will quickly take out the oil from the water. In our project, we will take the oil out of water according to many steps:

1) Start to mix the mixture with an air source like an air pump to stir that heterogeneous mixture with each other and make some air bubbles in the mixture.

2) Pour and add some iron filings to the tank.

3) That iron filings will stick on the bubbles of air, making a layer of iron-on those bubbles.

4) Use a magnetic field to attract the pollutants and the iron filings.

5) After repeating that process several times, the percentage of oil will decrease, and the water will be reused again in the same field.

According to the prototype, the prototype had been made of acrylic glass. Furthermore, the tallest pipe for entering the air source throw the air pump, the small pipe for the output of the pollutants and iron feelings as it shown in figure 6.

After testing that prototype, our project proved its success; $44 \%$ of the oil pollutants have been

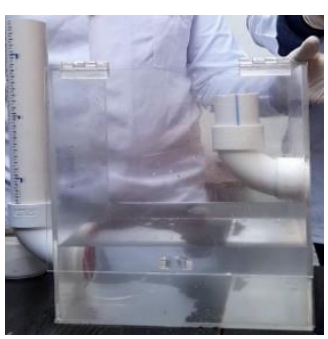

Figure 6 taken out from the tank. So, that water can be used again in the same field.

According to our testing results, when we put $100 \mathrm{gm}$ of oil and $120 \mathrm{gm}$ of iron feelings, the amount of iron feelings and the oil pollutants weights $164 \mathrm{gm}$. So, the amount of attracted oil is $44 \mathrm{gm}$ from the original amount that weighs $100 \mathrm{gm}$. By changing the amounts of the input of the oil and the iron feelings, we found that the project can attract $43 \%$ of the oily pollutants in water.

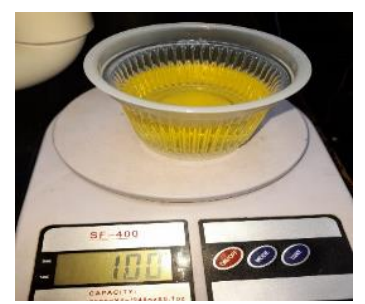

Figure 7

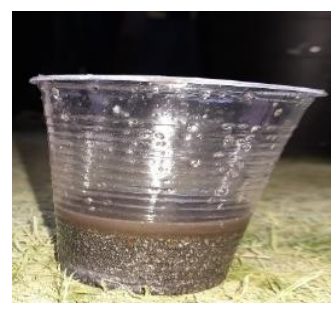

Figure 8

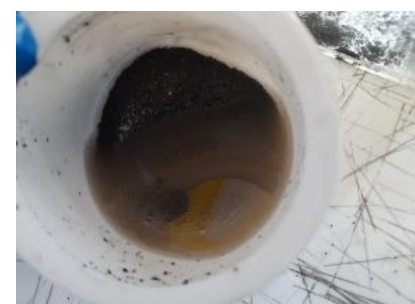

Figure 9 
The project achieved all the selected design requirements. First, the turbidity of the oily water after and before using our treating system. Before treating the polluted sample, the turbidity of the polluted sample was 589 NTU, while the purified sample has turbidity equal to $360 \mathrm{NTU}$. The other design requirements are measuring the oil and the grease and all extractable matter by chloroform. The polluted sample has a measure of $4.5 \mathrm{~g} / \mathrm{l}$, while the purified sample has a $3.7 \mathrm{~g} / \mathrm{l}$. All our analyses and measurables are certified by Integrated.

Management of Domestic \& Industrial Wastewater and Sludge and National Research Centre (NRC), Dokki, Cairo, Egypt.

Efficiency of the turbidity $(\tau)=\left(\frac{\tau_{0}-\tau_{f}}{\tau_{0}}\right) \times 100 \%$

Efficiency of the turbidity $(\tau)=\left(\frac{589-360}{360}\right) \times 100 \%$

Efficiency of the turbidity $(\tau)=39 \%$

Furthermore, the project is certified by University of Pennsylvania social impact center. The feedback from the University of Pennsylvania Center for Social Impact Strategy validation committee is Removal of oily waste from ship ballast water so it can be reused: Excellent use of a public narrative and articulation of problem statement. Excellent prototype generation and good examples of feedback on the prototype. Very good overall presentation. Highly innovative idea.

\section{CONCLUSION}

The state of increasing the usage of water will make us face a dilemma we will suffer from it which is the rarity of water sources and water quantities which considered as an enormous challenge but one of the best solutions for this challenge is to make processes that enable the reusing of water after using it in a process and use it in the same one or in new process, one of the process that make a massive consumption of water is the process of transportation of petroleum oil as after transporting it the containers in ships is filled by ballast water, our solution makes water available to reuse it after this process by using iron fillings, air pump and magnetic field, we have made test for our solution and it gave successful results as we had a container filled with water mixed with oil then we had air pump to stir them then we added iron fillings then made air pump into container then by magnets we have collect iron fillings then put the output out of the container, three trials had been made after each one we have calculated the quantity of output oil and how the water become more evident at the end the average percentage of the output oil is $40 \%$ of the oil in the container was filtered and became an output, so we concluded that our idea has been succussed to make water available to reuse so it will leads to decrease the consumption of water.

\section{RECOMMENDATIONS}

1. The project can be modified by using a safety insulated electromagnet instead of an ordinary magnet as it more power that can pull the iron filings with more oil, which will increase the efficiency of the project and reduce the cost.

2. Another recommendation is to use metal instead of iron filings as it has high cost and will not save money, so that we can use another metal which can be attracted by the magnet with more oil.

3. Removing oil from the metal fillings by a filtration process will give the opportunity to use that metal fillings again. So, it can be reused instead of using new metal fillings to be attracted to the magnet with the oil.

4. By increasing the number of magnets, the power of magnetic force will increase, so, that it will attract the metal fillings more and more with an immense amount of oil.

5. The last modification in the project will be the method of drawing oil from the water using a powerful magnet and wrapping it with a piece of plastic so that the iron filings do not stick to it and the magnet is placed inside a hose, so the oil is drawn from the surface of the water by pulling the iron filings in the water which will carry the oil with it. 


\section{LITERATURE CITED}

1. Hampton roads Sanitation District. (n.d.). Retrieved February 24, 2021, from http://uswateralliance.org/organization/hampton-roadssanitation-district

2. About Us. HRSD. (n.d.). https://www.hrsd.com/about-us.

3. Wastewater reuse: Eliminating discharge TO "Receiving Waters". (n.d.). Retrieved February 24, 2021, from http://www.virginiaplaces.org/waste/reuse.html

4. Eriksson, E., Auffarth, K., Henze, M., \& Ledin, A. (2001, December 06). Characteristics of grey wastewater. Retrieved February 24, 2021, from https://www.sciencedirect.com/science/article/abs/pii/S1462075801000644

5. Al-Jayyousi, O., T.. Asano, M., A.. Dixon, D., A.. Dixon, D., E.. Eriksson, K., I.. Fittschen, J., . . L.. Weizhen, Y. (1970, January 01). Evaluating greywater reuse potential for sustainable water resources management in Oman. Retrieved February 24, 2021, from https://link.springer.com/article/10.1007/s10661-007-9767-2

6. Canada, T. (2010, January 21). Ballast water defined. Retrieved February 24, 2021, from https://tc.canada.ca/en/marine-transportation/marinesafety/ballast-water-defined

7. Home. (n.d.). Retrieved February 24, 2021, from http://archive.iwlearn.net/globallast.imo.org/

8. Mohit, About Mohit Kaushik is a marine engineer sailing with Maersk Shipping. He handles website development and technical support at Marine Insight. Apart from handling web development projects, Mohit, A., Mohit Kaushik is a marine engineer sailing with Maersk Shipping. He handles website development and technical support at Marine Insight. Apart from handling web development projects, Says, *., Patrick, *., . . . Bruno. (2020, September 18). Procedure for cleaning fuel oil tanks on a ship. Retrieved February 25, 2021, from https://www.marineinsight.com/guidelines/procedure-for-cleaning-fuel-oil-tanks-on-a-ship/.

\section{AUTHORS}

i. Kirollos Remon Mounir

Email: remonmounir309@gmail.com

Mobile phone: +201275950449

ii. Fady Bola Samir

iii. Youssef Khaled Serageldin

iv. Moataz Mohamed Sabry 